Article

\title{
Exploring Participatory Microregeneration as Sustainable Renewal of Built Heritage Community: Two Case Studies in Shanghai
}

\author{
Xiaohua Zhong ${ }^{1, *}$ and Ho Hon Leung ${ }^{2, *}$ \\ 1 Department of Sociology, School of Political Science and International Relations, Tongji University, Shanghai \\ 200092, China \\ 2 Sociology Department, State University of New York College at Oneonta, Oneonta, NY 13820, USA \\ * Correspondence: xhzhong@tongji.edu.cn (X.Z.); hohon.leung@oneonta.edu (H.H.L.)
}

Received: 29 January 2019; Accepted: 11 March 2019; Published: 18 March 2019

\begin{abstract}
Since the 1990s, Shanghai has experienced massive urban development and renewal as ways to respond to its demographic, economic, and living space needs. Previous policies have led to the demolishment of many historical communities and valuable heritage housing. The existing ones continue to face extreme threats, such as bad physical conditions and the marginalization of communities. Yet there is a recent trend that emphasizes sustainable urban renewal named microregeneration (微更新), launched by municipal and local states since 2016. One of the main approaches of the initiative was to form new urban coalitions to focus on collaborative governance that helps integrate different agents' expertise and values for more sustainable urban developments and renewals. This paper explores two cases on how this concept has emerged. The first case is An Shan Si Cun (鞍山四村). This housing block was built in the 1950s for employees of some state-owned enterprises. The second case is Jing Lao Cun (敬老邨). This alley house neighborhood was built in 1930s for migrants who came to Shanghai. Furthermore, this paper is to explore and compare their approaches to sustainable urban renewal, which attempts to preserve these communities that represent cultural and built heritage in Shanghai. Specifically, this paper examines the challenges and accomplishments of these experiments, and discusses policy implications for future tactics of sustainable urban renewal.
\end{abstract}

Keywords: heritage community; preservation of living heritage; participatory microregeneration; heritage housing; Shanghai

\section{Introduction}

The term "heritage community" is meant to describe a social heritage area where residents live and interact with their neighbors and community members, under a historic backdrop of heritage structures. It is a community-based integration of tangible and intangible heritage [1,2]. Adopted in 2011, the UNESCO recommendation on the Historic Urban Landscape (HUL) was meant to integrate policy implementation and conservation of built heritage sites into the wider goals of urban development. The geographic setting becomes a key resource "in enhancing the livability of urban areas, and fosters economic development and social cohesion in a changing global environment" [3]. The HUL recommendation advocates that "communities in their quest for development and adaptation, while retaining the characteristics and values linked to their history and collective memory." [3] In the recommendation, heritage community is defined as a historic layering of social, cultural, and economic assets, which is produced by successive and existing culture, but vulnerable to urban redevelopment. Since rapid development may cause fragmentation and deterioration to urban heritage, 
it is important to integrate historic urban area conservation, management, and planning strategies into local development processes, instead of separate protection.

Although the integrated value of historic community as a living heritage has drawn local and global attention, the historic urban areas, especially the residential-use architectures and landscapes, is becoming increasingly vulnerable to urban development and renewal. Shanghai, being one of the most globalized and rapidly developed cities in China, is facing the challenge on how to preserve these vulnerable heritage communities. After the mass demolition renewal in the 1990s, the city began to establish a series of laws and regulations through different institutions and organizations, which have attempted to preserve as many heritage communities as possible. Heritage sites with structural resilience have the potential for redevelopment into luxury commercial spaces as a new attraction for cultural tourism. However, those in poor physical condition are the least desirable economic spaces for redevelopment, even though they have been designated a historical area. It is also a challenge to relocate the vulnerable residents who tend to be older and in low-income households in these areas. These efforts involve huge amounts of financial compensation for their relocation and a very lengthy period for resettlement. Another challenge in redeveloping these areas is to handle migrant workers who tend to choose to live in these areas. They have been drawn to cities for better job opportunities from rural areas and tend to choose to live in these "affordable" areas. How to rehabilitate the lower-quality residential-use heritages while balancing urban renewal and heritage conservation has become a critical question for the city. The purpose of this paper is to examine the two community-based renewal practices in Shanghai, to analyze the execution of these two projects, and to evaluate the achievements and challenges. The concept of preserving these urban and social heritage sites can be used to guide future research, analysis and evaluation on sustainable development.

\section{Literature Review}

\subsection{Heritage Community in the Urban Context}

The definition of "heritage community" within an urban context came from "Historic area/city", which was initially proposed in UNESCO's Recommendation Concerning the Safeguarding and Contemporary Role of Historic Areas (Nairobi Declaration, 1976). It refers to any group of buildings, structures, and open spaces, including archaeological and paleontological sites, constituting human settlements in a built environment. ICOMOS's Charter for the Conservation of Historic Towns and Urban area (Washington Charter, 1987) includes cities, towns, and historic centers or quarters, together with their natural and man-made environments in the scope of heritage community. Urban heritage comprises monumental heritage, nonexceptional heritage and new urban elements as urban space or infrastructure. The effort of preservation and development involves many stakeholders who constantly debate related concepts and approaches to policies, governance and management concerns. In addition to its architectural features and spatial fabric, the new concern has emphasized the continuity of local lifestyle and cultural practices as well as the place spirit, which are valuable assets in culturally-led urban regeneration projects [4].

In this context, we argue that urban heritage is not only the preservation of physical form but also a preservation of the intangible institutions and social networks that integrate into a broader definition of "heritage community". As the Faro Convention of Council of Europe emphasizes, "a heritage community consists of people who value specific aspects of cultural heritage which they wish, within the framework of public action, to sustain and transmit to future generations" [5].

\subsection{Community Participation as a Sustainability Indicator}

After bringing the notion of "community" back to heritage preservation, the living culture of people has been defined as an important part of intangible cultural heritage. The living culture of human communities, their evolution, and their continuing development are all essential elements of cultural heritage [6]. Besides the definition and assessment of significance of these intangible 
elements, there also comes the evoking of cultural right of communities. The United Nations Universal Declaration on Human Rights states: "Everyone has the right freely to participate in the cultural life of the community, to enjoy the arts and to share in scientific advancement and its benefits," [7], and the Faro Convention of Europe Council then recalls the community rights in heritage context, emphasizing the important aspects of heritage as they relate to human rights and democracy [7].

Studies suggest that community participation in heritage conservation improves residents' sense of belonging, facilitates the development of social networks, and inculcates a greater appreciation and understanding of the value of the local area [8-10]. Community participation has been a key aspect of sustainable development since it was clarified in the 1992 Rio Declaration. The principle of this declaration is to bring all concerned citizens "appropriate access to information" and "effective access to judicial and administrative proceedings" [11]. The HUL approach also advocates "civic engagement tools" involving a diverse cross-section of stakeholders, and empowers them to identify key values in their urban areas, develop visions that reflect their diversity, set goals, and agree on actions to safeguard their heritage and promote sustainable development [3]. These tools, which constitute an integral part of urban governance dynamics, should facilitate intercultural dialogue by learning from communities about their histories, traditions, values, and needs and aspirations by facilitating mediation and negotiation between groups with conflicting interests. Yet, the challenge remains regarding how to involve users and residents in the process of sustainably renewing a heritage community as a living complex.

Building on the definition of heritage community and cultural right, many community-based initiatives have been developed so far especially in Europe and North America, serving as the sustainable practices of heritage conservation, such as heritage committees, heritage walks, residents' cooperatives, urban revelation workshops, etc. Various case studies of community participation in heritage management try to answer questions such as "How and by whom were these concepts interpreted and reinterpreted, and what effects did they bring forth in their implementation? How do different actors play their roles and interact with each other? What is the creative and efficient ways of developing and managing community heritage assets with active civil society involvement? [12]"

\subsection{Empowered Participation as a Path to Sustainable Development}

The concept of sustainable development advocates more high-quality involvement of public participation [13]. When exploring how to make citizens play a more important role in sustainable urban renewal, some studies categorized the types and level of participation, as citizen-driven or government-organized [14,15], the ladder of participation [16], or coercive participation/induced participation/spontaneous participation [17].

In addition to these categories, the ongoing question is how to support and promote high-quality community participation for the sustainable preservation of heritage communities. To this end, some innovative bottom-up practices such as "empowered participatory governance" [18] and decentralized decision-making, such as "government-organized participation" [19], have been developed to explore and encourage collaboration and the practice of community joint ownership. As reference, Holden [20] discussed the practice of Sustainability Indicator systems (SIs) drawing upon the ideas of communicative rationality, pluralistic agonism, and governmentality. Rasoolimanesh, Jaafar, Ahmad, and Barghi [10] suggested the MOA (motivation-opportunity-ability) model to evaluate participation capacity.

Since the Rio Declaration [11], especially the HUL Recommendation [3], a number of studies focused on case collection and theoretical development of community participation in heritage conservation [21-24]. Sustainable heritage community renewal in an urban context includes not only the restoration of physical heritage, but also the inheritance of sense of place and intangible cultural heritage, as well as social sustainability (such as social cohesion), cultural diversity, and governance innovation. However, most of the research and practice focuses on the importance of 
community participation in preserving heritage. Few studies have investigated the factors influencing community participation, the quality of participation, its efficiency, and outcome.

The sustainability of cultural heritage management is strongly related to support from local community via participation. Although it is widely believed that public participation contributes to better projects, better development, and collaborative governance, most of the existing practices and researches are based on the developed Western context, which is totally different from rapidly industrializing socialist countries like China. Megacities like Shanghai have experienced a stronger redevelopment imperative, faster population growth, and less concern for urban heritage over the last three decades. Local community participation is especially limited, and yet, cities are exploring how different combinations of stakeholders and agents might be able to empower the community through innovative governance. Thus, by highlighting two case studies in Shanghai, this paper aims to examine whether new strategies of community-based participation and decentralized decision-making and empowerment can catalyze new trends of heritage community renewal.

\section{The Heritage Community Situations in Shanghai}

\subsection{Shanghai as Study Area}

With a population growing upwards of 25 million, Shanghai is the largest city in China with a fascinating urban history of more than 200 years. It underwent a series of urbanization episodes with the first wave beginning at the end of 19th century, and the second wave in the 1920s under Western colonial influence. Shanghai's population rose from one million by 1880 to almost four million by 1935, making it the world's sixth largest city. Among the newcomers, the number of foreign visitors increased by 40,000 per year in the early 1930s, the others were domestic migrants and refugees who moved to the city in the late Qing Imperial era [25]. As the Western entrepreneurs and local workers settled into the city, Shanghai had been actively engaged in architectural and urban renovation during the period, depending on the emplacement of the infrastructure upon which the foundations of modern urban life arose.

Shikumen Linong, sometimes translated as "lane houses", are two- or three-story structures resembling Western townhouses, as the heritage communities in central city today, emerged as the distinctive local style residential form during that period. As one of the earliest residential forms in urban Shanghai, the Linong originated from traditional South-facing architecture, was built into a cluster of rows, and, at scale, formed a residential compound. Linong-style architecture also marks the beginning of modern Chinese real estate, which has important status in the development of urban residences. Linong houses formed the largest and most concentrated segment of the residential landscape in Shanghai, and by the 1940s accounted for $72.5 \%$ of the city's residential buildings. This particular type of residence is symbolic of memories collectively shared by ordinary Chinese citizens and migrants [26].

As called the "adventurers' paradise" and "migrants' arrival city", Shanghai was remade into an industrial communist city after 1949. In order to accommodate the continuously increasing workers, a number of social housing estates were built by the Communist Government of China, portrayed as the 'model' modern housing for the working class. Between 1949 and 1978, two-thirds of the 17.56 million square meters newly built housing in Shanghai was the so-called "working class neighborhood" [27]. Since the 1980s urban redevelopment, most of the neighborhoods were demolished and replaced by residential high-rises. However, since the past two decades or so, postwar public housing has gradually received the recognition for its significant role in the mid-20th century as the memory of postwar reconstruction. In China, the trend began in the mid-2000s, not only for postwar significance, but also as "highly symbiotic of Communist China on political and ideological grounds" [28].

Like other global cities, Shanghai has faced critical challenges to balance urban development with heritage preservation. One the one hand, high density, overuse, and the lack of maintenance accelerated the aging and deterioration of these historical houses. On the other hand, the relocation and 
demolition policies driven by property-led principles of local government during the 1978 economic reform resulted in dramatic land use changes and socioeconomic inequalities. Since most of the housing heritages were state-owned, the entrepreneurialism had turned the government owners of historical buildings into the opposition against the protection of many unique heritage housing estates, such as Lilong and the working class neighborhood as described above. Destroyed by rapid urban renewal, the number of Lilong in Shanghai has significantly decreased from over 9200 sites in the 1950s to about 1900 in 2014 [29]. Meanwhile, most of the low-quality working class public housing with shared kitchens and bathrooms were replaced by high-rise commercial housing. The powerful trend of mass demolition and mass reconstruction resulted in the rapid disappearance of cultural heritage in the city.

In order to reduce the tension between development and conservation, the regulatory environment evolved to include new national and local laws on heritage preservation. District and subdistrict-level governments have developed a number of institutional innovations guided by the national policies, which have played a very active role in protecting urban heritage in China. The concept of "Historical Cultural Conservation Areas' (lishi wenhua baohuqu) was drafted in 1986. Simultaneously, the dynamism of the market economy and years of mass demolition for real estate accumulation led to the formation of a preservation movement. The value of "urban heritage" was recognized after the success of Xintiandi in the beginning of 2000 [30]. The Hong Kong developer and American architect behind Xintiandi project applied the strategy of "adaptive reuse" that had become prominent in the US and other countries since the 1970s. The project was quite successful in that it upgraded the image of Linong historic sites and created commercial activities, which transformed the old rundown residences into a hip, high-end shopping district which served as a cultural attraction to both local consumers and tourists. The Xintiandi project became a turning point of urban regeneration, because it not only amounted to an innovation of real estate development, but also evoked the value of residential heritage. However, in the Xintiandi case, heritage preservation was mostly driven by economic incentive by real estate developers or "state-sponsored gentrification" [31,32].

In 2003, the Shanghai Municipal Government promulgated the Regulations of Shanghai Municipality on the Preservation of Historic and Cultural Areas and Outstanding Historic Buildings (referred to as "Shanghai Preservation Regulations"). This was the first regulation on urban cultural heritage protection introduced at the local level in Shanghai and has constructed an overall legal framework for Shanghai [33]. Besides the commercialization of housing heritage, most heritage communities are still in residential use and require urgent conservation and a rapid improvement in living conditions. Since most of the historic residences are public property, the dominant way to improve such residences is government-funded renovation.

The Municipal 13th Five-Year Plan of Housing Development (2011-2015) reported that over 3.2 million square meters of the lower quality housing were rehabilitated by government funds which benefitted 136,000 households, and 5 million more square meters old housing were planned to be rehabilitated in the next five-year period [34]. The rehabilitation included adding private kitchens and bathrooms, reinforcing waterproofing on the roof, controlling termites, installing underground pipes and wires, and so on. Although the government paid hundreds of millions of dollars per year to repair these historic properties, most of the tenants were not satisfied. Ironically, residents of such heritage housing sites exploited the economic value of their living units, but did not value the preservation aspect of such housing. They rented out their residences for monetary gain, without concern for maintaining the property for historic preservation.

The heritage communities located in downtown Shanghai have suffered from growing problems of urban poverty and a deteriorating built environment, including the issue of rapidly deteriorating housing stock which has become a growing concern. From this point of view, neither commercial gentrification nor government-led rehabilitation can be the sustainable way of heritage community conservation. After decades of practice and reflection, the local state has become more adaptable and flexible in reconciling the seemingly competing goals and practices of urban redevelopment and 
heritage conservation. The challenge is how to provide and maintain the minimum quality of the existing housing to meet the modern standard of living and preserve the fast-disappearing heritage at the same time. At the present time, all levels of government are attempting to come up with solutions guided by the concept of sustaining and improving the quality of housing/living and preserving the living heritage at the same time.

\subsection{Methodologies}

Our research adopted a mixed methods approach to study how governance-based community participation might be a sustainable way of heritage community renewal. Through qualitative interviews and nonparticipatory observation, we explored how different agents might be able to empower and influence the community participation. In conducting historical comparisons, we were able to limit the community samples to cases that would help address the following theoretical question: How did major social transformation take place at a particular time? [35] Through the observation of community meetings and other informal discussions, we learned about the process of discussion, negotiation, and decision-making. We also identified the different requirements and actions of stakeholders, as well as tracked the social and spatial change.

The selection of these two cases was based on the representation of particular type of housing at different phases of the city development. Jing Lao Cun is a sample of a Linong community that represents the type of heritage community typical of colonial Shanghai. The historical residence is the memory of the city's very beginning of modernization and urbanization. The other case, An Shan Si Cun, represents a planned community that is the product of industrial Shanghai during the period 1950-1990, where China's urban population was largely immobile and governed through the socialist work unit (danwei). In this era, housing and other social services were distributed by the danwei. In both cases, the heritage communities developed during these economic transitions experienced numerous sociospatial changes that are reflected in the built environment.

We conducted intensive data collection between June 2016 and November 2018 throughout the urban renewal process by recruiting residents in the community for in-depth interviews [36]. With their oral informed consent, any willing resident in the neighborhoods we studied was free to share their experience and views about the microregeneration process as per their experience. We interviewed the community leaders and academic scholars who had firsthand experience in working with the locals about their working experience and relationship with other stakeholders, especially the local communities. Ten local officials, professionals, and the NGO leaders involved in these projects were also recruited for in-depth interviews. They were in professional positions and had relevant experience so that they were able to share their understanding of policy initiatives, governance structures, strategic actions, and decision-making. Furthermore, in order to understand how the local community residents and social organizations constructed their image of community and heritage value, how they conceived the microregeneration projects happened in their communities, we conducted in-depth face-to-face interviews with the people who lived and worked in these social settings. We also examined online forums and joined virtual discussions to gain further insight into the residents' views. In addition to the primary interview data we gathered, we also made use of extensive secondary resources including government policy documents, design plans, reports, and both mass media and social media as a methodology to gain understanding on the background of related policies pertained to urban renewal and heritage preservation.

\subsection{Case Introduction}

In the recent five years, as Xi Jin Ping's administration emphasized "people-centered philosophy of development," community-based governance became the main way to solve social problems, including heritage issues. Instead, a growth coalition between the strong municipal government and powerful real estate developers continues to drive urban redevelopment; therefore, more stakeholders, especially the local communities, are engaged by the rising importance of heritage conservation. 
This shift has turned the dominant role of the state in heritage conservation into a more balanced relationship. There has been more grassroots involvement and collaboration of more nongovernment stakeholders. Simultaneously, the national and local government in China launched the Social Governance Innovation Initiative in 2016 in response to social inequality and improving poor living conditions. The main tasks stressed a number of social concerns that in fact facilitated grassroot involvement as a way to improve quality of life and social services [37].

As the response from local government implementation, the idea of "community governance" was involved in Shanghai's recent policies of urban renewal and heritage conservation, by listing the ideas of activating community through urban renewal, improving space quality based on community requirements, and encouraging public participation in heritage management. In order to regulate and supervise the sustainable process of urban renewal, in 2015, the Shanghai government promulgated a series of policies such as The Implementation Measures of Shanghai Urban Regeneration (2015) that marked a new stage of urban regeneration. Since then, urban regeneration has become more focused on the principles of public participation, stakeholder collaboration, and classification implementation [38]. Since the beginning of 2016, a government-led plan-“microregeneration"-has been launched by the municipal urban planning sector and operated by subdistrict governments (the third level government of Shanghai, following municipal and district level). All the projects aim at the renewal of public space, such as public green, parking spaces, and public infrastructure in the old downtown area or historic communities, supported by easy access to government funding. As mentioned before, these heritage communities are state-owned and managed by public property management corporations. Thereby, the "microregeneration" is the government's responsibility. One of the main approaches of the initiative was to form new urban coalitions to focus on collaborative governance that would help integrate different agents' expertise and values for more sustainable urban developments and renewals [39].

The two cases we chose are the experimental projects of community-based heritage renewal in this background. They are both located in the municipal-level historical and cultural conservation area where housing quality is low. They have been designated as pilot projects for small-scale regeneration as a way to experiment the effectiveness of more transparent and efficient conservation strategies by the Municipal Bureau of Urban Planning (see Figure 1).

An Shan Si Cun was built in the 1950s and is located in Siping subdistrict, Yangpu District, in the northeast of Shanghai. It is a typical working class community that represents the industrial development of Shanghai in 1950-1960s. The community has 75 buildings with 2765 households. In the 1990s, all the apartment buildings were rehabilitated with use of the municipal fund, which resulted in great improvement of living conditions, but the public green remained untouched. This research focused on investigating the process of building this community garden since 2017.
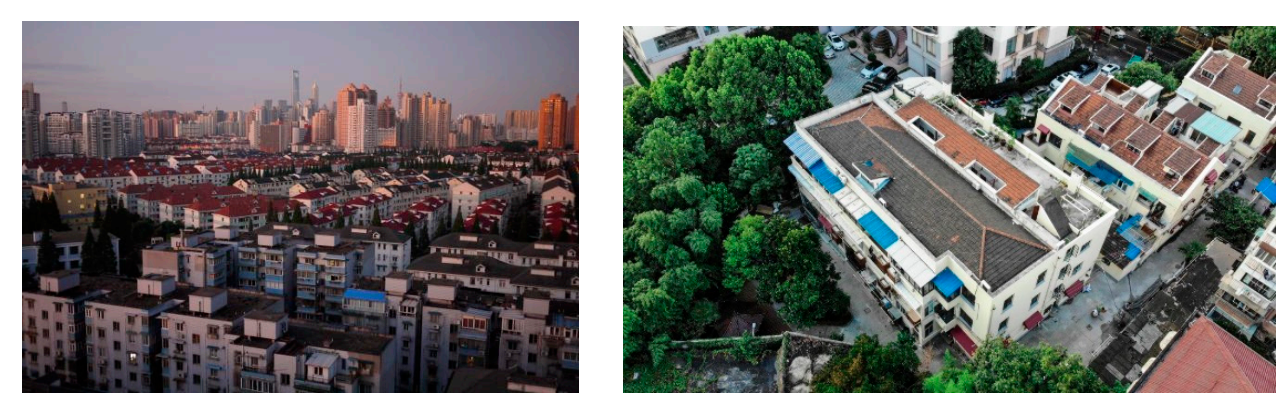

Figure 1. An Shan Si Cun (left) and Jing Lao Cun (right). Source: Shanghai Microregeneration Action Plan (local planning scheme).

Built in 1948, Jing Lao Cun is located in Lane 693, Xin Hua Lu subdistrict, Changning District, Shanghai. It was formerly known as Anhe Village. There are three buildings in this small district with 44 households of 126 residents. There was a high ratio of elderly residents. Due to poor living 
conditions in this old neighborhood, residents there were eager to collaborate to improve their living environment. The renewal process of the shared public space has taken place since 2018.

\section{Case Analyses}

\subsection{Case 1: Community Garden in a Working Class Neighborhood}

An Shan Si Cun is one of the largest working class neighborhoods remaining in Shanghai. These large-scale neighborhood compounds, consisting of 4-6-story brick-and-mortar houses, were built environments emblematic of the transition from industrial to postindustrial Shanghai circa 1950s to 1980s. The construction of housing in this era was to provide sturdy living quarters to the workers who worked in the nearby factories. Nearly two-thirds of the newly built housing during this period were such neighborhoods. Its namesake, "working class community", has been designated as the heritage of industrialization.

Since the economic reform, most of these working class communities have been demolished. The remaining residences were privatized under the housing reform under the broader economic agenda. After the People's Republic of China was founded in 1949, the land and real properties were gradually nationalized. In the late 1980s, there was a land and real property system reform. Land rights came with a specified term of use and had been brought into the market in the form of auctions, but the state retained land ownership. In 1988, the "housing property right reform", which targeted the original publicly-owned housing (referred to as "public house"), was enacted. Under this reform, public houses were sold to individual owners at a preferential price set by the government.

Residents in the neighborhoods had historically shared the kitchens and bathrooms on each floor. In order to put the "qualified" houses and their units in these houses onto the market, the unit areas must be distinguishable from each other. Each unit must be equipped with a private kitchen and bathroom. Under this new policy on housing ownership, the Government in the An Shan Neighborhood decided to add an extra floor on the roof so that more spaces in the building could be used for private bathrooms and kitchens. At the time, this move was considered very innovative. Thus, this project won the National Habitat Environment Model Award from the Ministry of Construction in China in 2007.

In spite of improvement of the living conditions, lack of public space is still one of the severe problems in these heritage communities. Therefore, the Community Garden Project was initiated as one of the pilot projects in "microregeneration" since the beginning of 2016. The garden is located in the central square of the neighborhood. The square used to be an abandoned lot due to the lack of maintenance. In 2016, the Siping Subdistrict Government, whose jurisdiction covers both the neighborhood and Tongji University, the education institution located near the neighborhood, designated the Community Garden as a model project for community building. Professor Liu in the Department of Landscape Designing, Tongji University, and his social enterprise, were invited to be the designer and executor of the project.

After the preliminary investigation, Professor Liu and his team found that there were 6800 residents in the neighborhood, $23.5 \%$ of whom was over sixty years old, signaling an aging population. Many middle-income families with children chose to reside there due to the many well-known elementary schools in the neighborhood. In order to develop a design that could satisfy the residents' needs, the subdistrict government and residents' committee helped the team to organize various community meetings where residents of different ages voiced their views. Finally, the garden was positioned as a space to meet the needs of residents for leisure activities, parent-child interaction and botanical education.

In order to ensure sustainable management of this garden project, the initiators invited residents to participate in the conceptual design and construction processes, while encouraging residents to take ownership and manage the garden themselves. Two projects were developed out of this initiative: (1) The Fangling Flower Club, a self-governing social organization, initiated by a group of gardening 
enthusiasts in the community who wanted to share their experience in tending gardens with one another, and (2) a newly launched education program for "future landscape architects" that encouraged children to exercise their imagination to help design the space. In this case, the empowerment of various older community groups and the formation of new neighborhood associations formed a different community governance structure from previous governance practices where the local government took control of the maintenance. Now, the two groups of volunteers were empowered to take responsibility for stewardship of the garden with the help of Professor Liu and his team (see Figure 2). Note that the funding for maintenance continues to come from the subdistrict level government.

The garden became a model of community empowerment and urban renewal in high-density heritage communities. Many residents have described the transformation of this shared public space in the old neighborhood into a shared "living room" for resident interactions around plant education, cultivation, and strengthening neighborly social connection. At the same time, community gardens are also supposed to enhance residents' overall management capacity, increase the awareness of community ownership, and realize residents' self-governance [40].

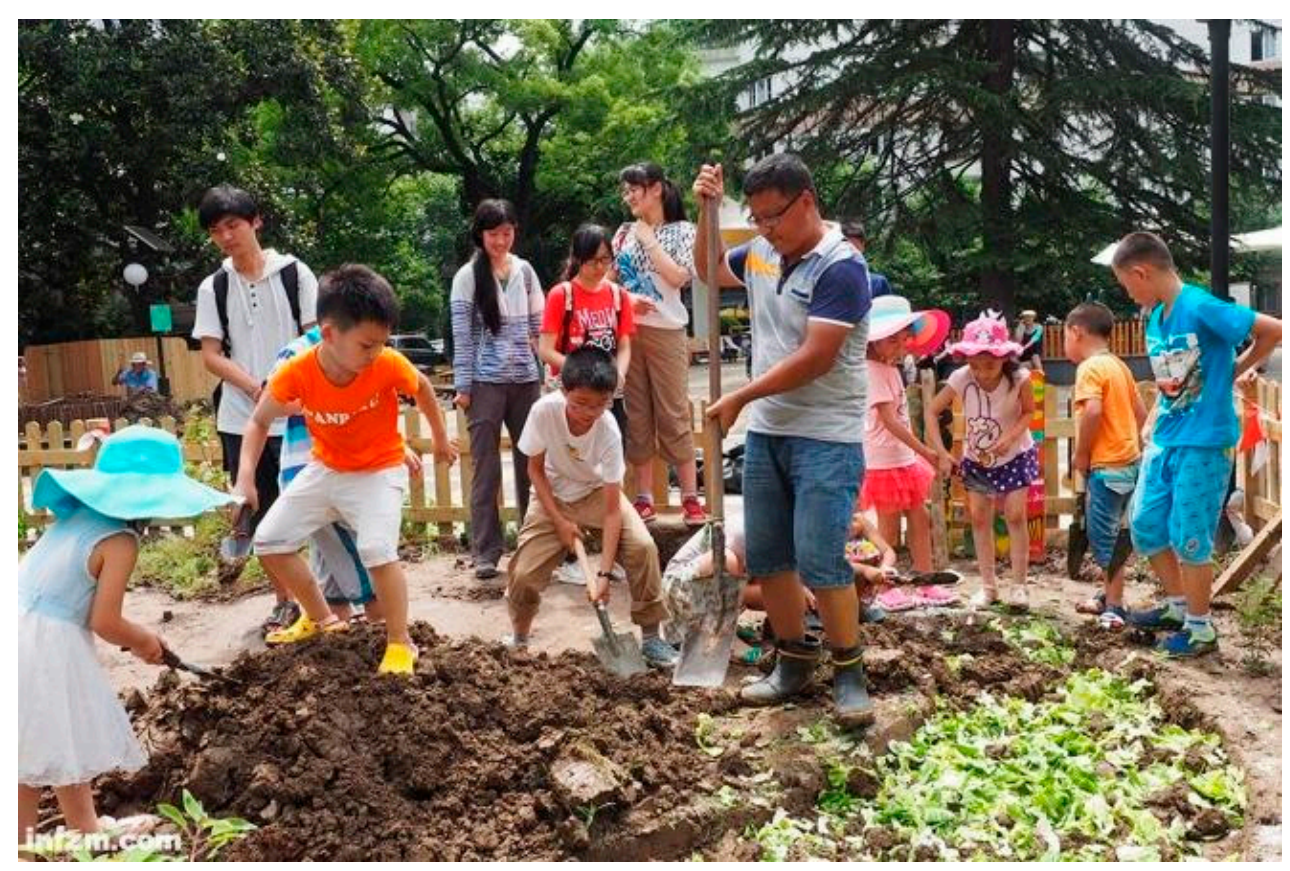

Figure 2. The children joined the construction process in An Shan Si Cun. Source: Shanghai Four-Leaved Clover Natural Education Organization.

\subsection{Case 2: Microregeneration in a Historic Downtown}

Xinhua Lu Area, where Jing Lao Cun is located in, was built in 1925 during Shanghai's concession period, and, in 2005, was designated a "Historic and Cultural Area" by the municipality. Along the main street, there are more than 120 villas in various architectural styles, with most of them built by colonizers from the UK, Germany, the United States, the Netherlands, and Italy. Xinhua Lu was once called the "Foreign Lilong Museum", where many high-class foreign immigrants gathered. However, the historic built environment has suffered structural degradation over the years. When the communist party took over in the 1950s, these historical residences were redistributed to many people in need. In the late 1990s, more commercial housing was developed in order to meet the needs of an influx of migrant workers settling in the neighborhood. In 2017, the Xinhua Lu subdistrict government started the microregeneration project as a response to the citywide initiative to improve public space, pedestrian sidewalk, and aging facilities. Contrary to the way previous renewal projects had been funded, the Xinhua Lu project was only partially funded by the local government; the remainder of funds came from investors and social enterprises. 
Vanke, one of the biggest domestic real estate developers, played a crucial role in the regeneration process. Vanke had been converting a 100-year-old Columbia Country Club nearby into commercial and office use. At the same time, Vanke saw advantage to exercising corporate social responsibility in the neighborhood by supporting some small-scale renewal in historic communities. Jing Lao Cun was one of the sites. The main objective of this microregeneration project was to improve the spatial quality and built facilities in these old neighborhoods, for example, repairing roads, increasing spatial utilization by integrating underused public space, and adding exercise equipment for public use. Many rounds of consultation and discussion among the parties involved led to a workable project. (see Figure 3)

Together with the subdistrict government, Vanke and other social enterprises and NGOs were empowered to redesign this heritage community. One of the partners was the $\mathrm{Da} \mathrm{Yu}$ (Big Fish) Community Empowerment Association, a nongovernmental organization established in 2017. There are five cofounders of the organization, four of whom are architects; another is a doctoral student of urban studies. The cofounders of Da Yu are representative of a growing number of young professionals, mainly in their thirties with the experiences of studying or working abroad, who are concerned about the relationship between urban renewal and community empowerment, and have taken it upon themselves to work as advocates and conflict mediators to nurture the historically tense citizen-administrator relationships. The Da Yu cofounders saw their role as creating a "catfish effect" in these heritage communities by mobilizing and empowering residents to participate in projects that directly affect their everyday lives. The collaborative relationship between these agents emerged spontaneously, as they became friendly, shared creative ideas in evolving the future of the community and, ultimately, influenced funding.

This participatory urban renewal project not only attracted the elderly participants, but also empowered many young and middle-aged residents. Da Yu, other NGOs, and social enterprises mobilized participants through social media, inviting residents to trendy events, neighborhood walks, festival celebrations and other relaxed encounters as a new forum to particulate in urban renewal. Such events strengthened a sense of community belonging, and engaged residents in microregenerations; more and more residents began to express their requirements and advices for community facilities and public space. In the case of Jing Lao Cun, the community committee first raised an idea of building a small pavilion in a public space for the elderly, but soon realized there was a lack of professional support. One of the founders who lived in the neighborhood heard about the proposal and came to the committee voluntarily. He helped them complete the design for the pavilion in addition to assisting in the design of a comprehensive neighborhood plan. High value voluntary efforts like this helped the NGO build trust in the community and foster a good relationship with the subdistrict government, which helped smooth the renewal process.
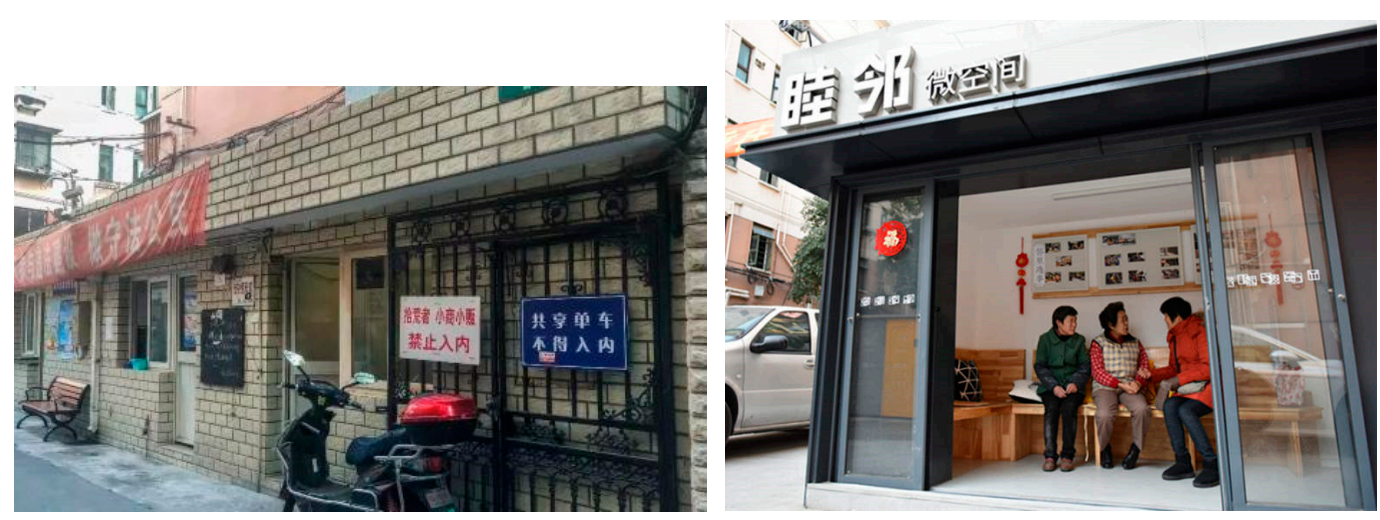

Figure 3. The participation-based design of a public space in Jing Lao Cun. Before (left): the abandoned public telephone booth and mail room in the entrance of neighborhood. After (right): the comfortable neighborhood club. Source: Da Yu Community Empowerment Association. 


\subsection{Case Analysis and Discussion}

Historically, the rehabilitation of public housing single-handedly carried out by the subdistrict government was fiscally burdensome. Furthermore, these short-term rehabilitation projects had not historically engaged residents and involved them in the planning process. Often times, the outcome was far from satisfactory. Under the new social governance institutions and new urban renewal initiatives, residents themselves are empowered to get involved in the process of transforming their own living and neighborhood spaces. The broader research implications from these cases impact how to make public participation more conducive to heritage renewal and sustainable preservation. Although these two cases merely began as neighborhood pilot projects, observations and analysis of the cases indicate some key factors that could affect the quality and efficiency of community participation. Two factors are worth careful examination: participant capacity and the citizen-administrator relationship.

\subsubsection{Participant Capacity}

Participant capacity refers to the residents' awareness and knowledge about heritage value, community belonging, and involvement in conservation and urban development processes. Both the residents and their community organizations in the two cases lacked specific and needed ideas for empowered decision-making and technical expertise required for spatial reconfiguration and transformation. Furthermore, the residents in these two cases were not aware of the historic and intangible value of their existing residences. They welcomed improvements on their public spaces, but did not have specific ideas on what changes might be beneficial in the longer term. Although the subdistrict governments had been managing and improving the communities under their jurisdiction, they had very little experience incorporating resident participation and opinions.

Through our research we discovered that multiple stakeholders, such as the university professor, NGOs, social enterprises, and various agents from other business and private sectors, acted as an enabling factor to empower residents with necessary knowledge and skills, and even the financial resources to make the desired changes to their heritage community. While the current microgeneration experiment continues to follow the usual "top-down" structure in Chinese cities, the encouragement for active involvement of the locals have attracted younger residents who are eager to contribute and test out new ideas.

In the first case, most of the residents are retired working class or migrants with little knowledge and capacity of community participation. The initiators helped to empower the community through government-organized public participation. By listening to their concerns and having them involved in the construction and maintenance for their garden, the residents were in an active and participatory process where they had developed a sense of accomplishment of group goals. As Professor Liu, the project manager, said in the interview (September, 2016):

"It's difficult to gain the multiple tasks of the project through urban spatial planning. The government intended to enhance the quality of public space, strengthen the compound use of land, and motivate community residents to participate in designing, maintenance and management ... We have to mobilize and train the residents in the early phase of the project."

In the second case, more and more middle-income youths moved to the gentrified downtown community with higher education background and participation capacity. As one of the cofounders of Da Yu said in the interview (August, 2018):

"Our purpose is to enhance community belonging of the residents through spatial improvement and interesting activities, to attract these educated youth participate in heritage conservation."

In these two cases, we find that collaboration among the subdistrict government, academics and professionals, community organizations, and neighborhood residents yields a more satisfactory plan for heightened livability of heritage communities where residents benefit from the renovations and are empowered to make decisions through participation. 


\subsubsection{Citizen-Administrator Relationship}

Research in these cases reveals that the citizen-administrator relationship is another key factor that determines the capacity for innovative governance, especially in China's strong government institutions. A sustainable, long-term renovation plan for a heritage site must take a multifaceted approach to urban renewal, particularly the residents' needs. It goes without saying that good communication between the city administrator and citizens yields better results. Historically, the local government and administrators played a dual role in public participation. On the one hand, they mobilized participation and helped create the preconditions for citizen empowerment by providing information and resources; on the other hand, they could influence the outcome of public participation by working with the residents. Since there is an inevitable gap between bureaucratic reality and participant expectations, both citizens and administrators might encounter risks of becoming impatient in the development process, expecting different outcomes and, in the worst case, eroding trust. Both the professionals and community organizations in the two cases play the role as the third party bridge which facilitates negotiations to reach a reasonable compromise between parties and coordinate different interests and expectations. They have a concomitant understanding of local political structures and a good relationship with local government and administrators. They are deeply involved in the communication process, so they can understand and interpret the purposes of the policies and public requirements to each other by using their professional skills. The difference is that conventional top-down practice has historically dominated the bureaucratic system, such as procedural constraints and budget auditing. This newly emerging participatory practice, involving third parties and residents, has many opportunities to influence decisions by prioritizing the heritage sites and purposes of microregeneration projects. In the second case, the beneficial involvement of private sector developer, Vanke, contributed financial and social resources to the process of neighborhood renewal.

As a subdistrict official said in the first case stated (April, 2017):

"It's a big challenge for us to govern the working class neighborhoods. They are in high-density poor living conditions with a lack of public facilities. As more and more migrants moved in, the needs of the residents became more diverse. It's difficult to know what they need. The community garden project became a trigger to activate the community, to cultivate their self-governance."

But in the second case, the investor and professionals played an active role to negotiate between the residents and administrators. As one of the Da Yu cofounders reflected (September, 2018):

"Vanke as the investor intends to attract more creative class to work and live in the community. But for us, we are trying to find a way to realize our professional dream, and make our design more socially sustainable."

\section{Conclusions}

This paper aims to explore how to preserve living heritage and heritage housing in a rapidly developing Chinese city, like Shanghai, where there is a massive expansion of population and a need to rehabilitate existing housing stock to meet the demands of urbanization. The heritage houses, which were built in the late 19th century and early 20th century, are usually 3-story-type row houses in a villa style. Other heritage housing includes those for the "working class community" built in the 1950s-1960s. Aggressive housing development and reform were not implemented until 1990s. A short-term solution is to replace these low-rise housings with modern condominiums. These heritage houses and communities not only face natural deterioration and overuse, but also demolition. Shanghai has been working hard to preserve heritage with various policies and strategies while balancing the city's needs. In addition to all the aforementioned challenges, how does the city improve the living quality of the existing residents who inhabit these deteriorating heritage residences? Even though the subdistrict governments have carried out different phases of renovation in various communities in the past, the short-term rehabilitation strategies and outcomes are less than desirable.

Inspired by recently developed Historic Urban Landscape recommendations advocated by UNESCO, best practices should not only preserve the physical structure of a piece of tangible heritage 
but also the intangible cultural and social values in it. Without people and without culture and social interactions, the heritage structure is no more than a "material organization" and a facade. Our research seeks to inquire how different stakeholders carry out sustainable preservation where the residents can continue to live with their cultural and social practices in these heritage communities. The city and subdistrict governments are experimenting with different participatory microregeneration practices. The two case studies introduced here illustrate this process and report some preliminary results.

The concept of materializing living heritage perseveration should come from the residents who not only value their cultural and social practices but also the heritage value of their living environment. Thus, residents show strong sense of belonging to their community and they treasure their built environment. Our observation and analysis note that many current residents did not have high awareness of the heritage value of their places. When asked what they would like to improve their public spaces, many of them did not have the capacity to express their thoughts and ideas. The subdistrict governments did not have much experience in consulting the residents' needs. This study found that inviting third parties that had expertise on planning, designs, and skills on mobilizing the residents was a very promising move. Having business partners in the community that can contribute not only knowledge to the preservation but also financial resources benefit both the subdistrict governments and the residents. In short, collaboration of different stakeholders with empowered residents can lead to sustainable preservation of living heritage. In short, the research focus should continue to observe and analysis the outcome and evaluate long-term impact of this approach on to all stakeholders, particularly the residents. Cross-case comparison in Shanghai and other cities in China should be systematically conducted so that the policies and practices can be revised and refined.

Yet what are the implications of the preliminary findings for the continuing effort of preserving living heritage in Shanghai and China in general, and in the concept of sustainable preservation of living heritage? Since these two cases are recent, and the design of the second case, in particular, has not yet fully materialized, our research suggests a longitudinal follow-up. Here can be some productive speculations. According to similar projects in other countries such as Melaka, Malaysia [41], the residents in the studied villages felt that they were able to develop their cultural pride and identity to their community members and their society. Historic preservation of housing in Houston, Texas, shows that it could be a way to challenge the forces of gentrification, displacements, and large-scale demolishment of a neighborhood [42]. It seems what Shanghai is pursuing regarding the preservation of living heritage is on the 'right track' with foresighted vision, joining the global community to safeguarding of intangible cultural heritage [7]. Some might also view the promotion of participatory approach to community development through preserving living heritage is a step closer to opening more room for democracy. While hoping for the best developments in Shanghai, in particular, and China, in general, one challenge to these preservation cases remains: the quality of living in these housings. Even though pervious renovations, as discussed above, had some significant improvement of the living environment, some view this government-led plan "microregeneration" as "project on face" (面子工程) which is only a very "superficial" renovation. No matter what to do to these housings, they will not last, since the structures have been overused and weakened by termites. Thus, the current success might be short-lived.

What can be suggested and thought more thoroughly is in the following. While preserving these heritage housings is desirable and urging, it would be more productive to reevaluate the quality of these designated sites, whether it is humanely and financially feasible to preserve them all; whether the city government will come up more affordable and innovative measures to resettle the residents if their housings are not deemed to be kept. Furthermore, preservationists, policy-makers, and other stakeholders might think further that other than the built heritage what are "the essential elements representing the living culture of human communities, their evolution and their continuing development" [7]. Would planners, designers, architects, related experts, and citizens sustain the cultural practices in other settings, such as in productive and quality community living [43]? Preserving 
both of the built environment and the intangible cultural heritage should be ideally the priority. Yet not all the preservation projects offer the ideal situations. Physical environments could be just a medium where citizens and active agents create and recreate their everyday living culture. Proper policies to balance both preservations should be welcoming.

Author Contributions: Conceptualization, X.Z. and H.H.L.; formal analysis, X.Z. and H.H.L.; investigation, X.Z.; writing—original draft preparation, X.Z.; writing, review \& editing, X.Z. and H.H.L.

Funding: This work was funded by the National Natural Science Foundation of China (Grant No. 51678416).

Conflicts of Interest: The authors declare no conflicts of interest.

\section{References}

1. Rosa, F.; Palma, D. Historic Urban Landscape Approach and Port Cities Regeneration: Naples between Identity and Outlook. Sustainability 2013, 5, 4268-4287. [CrossRef]

2. Zhong, X. Social Resilience of Heritage Communities: The Conservation of Urban Heritage in the Perspective of Risk Management. Chin. J. Urban Stud. 2016, 3, 25-30.

3. UNESCO. Recommendation on the Historic Urban Landscape; UNESCO World Heritage Center: Paris, France, 2011.

4. European Union Research Report. Sustainable Development of Urban Historical Areas through an Active Integration within Towns; OPOCE: Luxembourg, 2005.

5. Council of Europe. Faro Convention or Council of Europe Framework Convention on the Value of Cultural Heritage for Society; Council of Europe: Strasbourg, France, 2005.

6. Zagato, L. The Notion of "Heritage Community" in the Council of Europe's Faro Convention. Its Impact on the European Legal Framework. In Between Imagined Communities of Practice Participation, Territory and the Making of Heritage; Göttingen University Press: Göttingen, Germany, 2015.

7. Lenzerini, F. Intangible Cultural Heritage: The Living Culture of Peoples. Eur. J. Int. Law 2011, 22, 101-120. [CrossRef]

8. Tosun, C. Host perceptions of impacts: A comparative tourism study. Ann. Tour. Res. 2002, 29, 231-253. [CrossRef]

9. UN-Habitat. Inclusive and Sustainable Urban Planning: A Guide for Municipalities; UN-Habitat: Nairobi, Kenya, 2007.

10. Rasoolimanesh, M.; Jaafar, M.; Ahmad, G.; Barghi, R. Community participation in World Heritage Site conservation and tourism development. Tour. Manag. 2017, 58, 142-153. [CrossRef]

11. UNESCO. The Rio Declaration on Environment and Development; UNESCO: Rio, Brazil, 1992.

12. They Are Identified by the Faro Community and Included in Faro in Action, an Active Learning Platform Gathering Good Practices and Promoting Exchange and Dialogue among Practitioners, Facilitators and Heritage Actors. Available online: https://www.coe.int/en/web/culture-and-heritage/faro-convention (accessed on 10 February 2019).

13. Melo, M.; Baiocchi, G. Deliberative Democracy and Local Governance: Towards a New Agenda. Int. J. Urban Reg. Res. 2016, 30, 587-600. [CrossRef]

14. Simonsen, W.; Robbins, M. Citizen Participation in Resource Allocation; Westview Press: Boulder, CO, USA, 2000.

15. Wandersman, A. Citizen Participation. In Psychology and Community Change: Challenges of the Future; Brooks/Cole: Pacific Grove, CA, USA, 1984.

16. Arnstein, S. A ladder of Citizen Participation. J. Am. Plan. Assoc. 1969, 35, 216-224. [CrossRef]

17. Tosun, C. Towards a typology of community participation in the tourism development process. Anatolia 1999, 10, 113-134. [CrossRef]

18. Fung, A.; Wright, E. Deepening Democracy: Institutional Innovations in Empowered Participatory Governance; Verso: New York, NY, USA, 2003.

19. Buckwalter, N. The Potential for Public Empowerment through Government-Organized Participation. Public Adm. Rev. 2014, 74, 573-584. [CrossRef]

20. Holden, M. Public participation and local sustainability: Questioning a common agenda in urban governance. Int. J. Urban Reg. Res. 2001, 35, 312-329. [CrossRef] 
21. Yung, E.; Chan, E.; Xu, Y. Sustainable Development and the Rehabilitation of a Historic Urban District-Social Sustainability in the Case of Tianzifang in Shanghai. Sustain. Dev. 2014, 22, 95-112. [CrossRef]

22. Keitumetse, S. Sustainable Development and Cultural Heritage Management in Botswana: Towards Sustainable Communities. Sustain. Dev. 2011, 19, 49-59. [CrossRef]

23. Jimura, T. The impact of world heritage site designation on local communities: A case study of Ogimachi, Shirakawa-mura, Japan. Tour. Manag. 2011, 32, 288-296. [CrossRef]

24. Choi, H.C.; Sirakaya, E. Sustainability indicators for managing community tourism. Tour. Manag. 2006, 27, 1274-1289. [CrossRef]

25. Macpherson, K.L. Shanghai's history: Back to the future. Harvard Asia Pac. Rev. 2002, 3, 37-40.

26. Lu, H.C. Beyond the Neon Lights: Everyday Shanghai in the Early Twentieth Century; University of California Press: Berkeley, CA, USA, 1999.

27. Yang, C. The Spatial Practice of Socialist City: Shanghai Working-class Neighborhood (1949-1978). Hum. Geogr. 2011, 119, 35-40.

28. Wang, Y.W.; Zhang, X.; Sun, L. Valuing workers' housing as heritage of post-liberation China: Measuring public perception of Caoyang New Village, Shanghai. In Structural Studies, Repairs and Maintenance of Heritage Architecture XIV; WIT press: Southampton, UK, 2015; pp. 517-529.

29. Zhang, C. Research on the Heritage Value and Conservation Practice of Shanghai Lilong Residence. Unpublished. Ph.D. Dissertation, Tongji University, Shanghai, China, 2014.

30. Zheng, S. Urban Regeneration and Conservation of Historic Architecture in Shanghai. J. Chin. Acad. Sci. 2017, 32, 690-695.

31. Ren, X. The Political Economy of Urban Ruins: Redeveloping Shanghai. Int. J. Urban Reg. Res. 2014, 38, 1081-1091. [CrossRef]

32. He, S.; Wu, F. Property-Led Redevelopment in Post-Reform China: A Case Study of Xintiandi Redevelopment Project in Shanghai. J. Urban Aff. 2005, 27, 1-23. [CrossRef]

33. Zhong, X.; Chen, X. Demolition, Rehabilitation, and Conservation: Heritage in Shanghai's Urban Regeneration, 1990-2015. J. Archit. Urban. 2017, 41, 82-91. [CrossRef]

34. Shanghai Bureau of Housing. The Municipal 13th Five-year Plan for Housing Development (2011-2015); Shanghai Bureau of Housing: Shanghai, China, 2011.

35. Neuman, W.L. Social Research Methods: Qualitative and Quantitative Approaches, 6th ed.; Pearson: London, UK, 2013.

36. Strauss, A.; Corbin, J. Basics of Qualitative Research: Technique and Procedures for Developing Grounded Theory, 2nd ed.; Sage: Newbury Park, CA, USA, 1998.

37. CPC. Report on the 19th National Congress of CPC; People's Literature Publishing House: Beijing, China, 2017.

38. Shanghai Bureau of City Planning and Land Management. The Implementation Measures of Shanghai Urban Regeneration; Shanghai Bureau of City Planning and Land Management: Shanghai, China, 2015.

39. Gerometta, J.; Haussermann, H.; Longo, G. Social Innovation and Civil Society in Urban Governance: Strategies for an Inclusive City. Urban Stud. 2005, 42, 2007-2021. [CrossRef]

40. UN-Habitat. Shanghai Manual Annual Report; UN-Habitat: Shanghai, China, 2017.

41. Aziz, R.A. Heritage Conservation: Authenticity and Vulnerability of Living Heritage Sites in Melaka State (in Kajian Malaysia). J. Malays. Stud. 2017, 35, 39-58.

42. Ryberg-Webster, S. One step ahead of the bulldozer: Historic preservation in Houston, Texas. J. Urban. Int. Res. Placemaking Urban Sustain. 2019, 12, 15-33. [CrossRef]

43. Wellman, B.; Leighton, B. Networks, neighborhoods, and communities: Approaches to the Study of the Community Question. Urban Affairs Q. 1979, 14, 363-390. [CrossRef]

(C) 2019 by the authors. Licensee MDPI, Basel, Switzerland. This article is an open access article distributed under the terms and conditions of the Creative Commons Attribution (CC BY) license (http:/ / creativecommons.org/licenses/by/4.0/). 